\title{
The Role of Executive Functions in Language Comprehension in Preschool Children
}

\author{
Sanja Šimleša*, Maja Cepanec, Marta Ljubešić \\ Child Communication Research Lab, Faculty of Education and Rehabilitation Sciences, University of Zagreb, Zagreb, Croatia \\ Email: *s.simlesa@gmail.com
}

How to cite this paper: Šimleša, S., Cepanec, M., \& Ljubešić, M. (2017). The Role of Executive Functions in Language Comprehension in Preschool Children. Psychology, $8,227-245$.

http://dx.doi.org/10.4236/psych.2017.82013

Received: November 3, 2016

Accepted: January 20, 2017

Published: January 23, 2017

Copyright $\odot 2017$ by authors and Scientific Research Publishing Inc. This work is licensed under the Creative Commons Attribution International License (CC BY 4.0).

http://creativecommons.org/licenses/by/4.0/

\begin{abstract}
The aim of this study was to examine the relationship among various aspects of executive functions (inhibitory control, working memory, planning and cognitive flexibility) and language comprehension in preschool children. The final sample included 203 children, four or five years old, with average nonverbal cognitive development. The measuring instruments for assessment of the children's executive functions were Grass/Snow task; Inhibition task (NEPSY-II); Digit Span task; CANTAB tasks and Dimensional Change Card Sort. The Reynell Developmental Language Scales were used for the assessment of language comprehension. The results showed that the only significant predictors of language comprehension were verbal working memory, as measured by the Digit Span task, and inhibitory control, as measured by the Grass/Snow task. This study emphasises the importance of inhibitory control and working memory for language comprehension in preschool children.
\end{abstract}

\section{Keywords}

Executive Functions, Language Comprehension, Preschool Children

\section{Introduction}

Language comprehension has been studied considerably less than language production. Studies dealing with language acquisition have been more focused on language structure in children than on language comprehension. Moreover, the "cognitive infrastructure", included in both "breaking" the language code and the comprehension of a complex symbolic system (like language), has been largely understudied. Research has mainly focused on the influence of input features, the sensory features of children, and general cognitive status (intelligence). There have been almost no studies on the specific cognitive processes involved in language comprehension development and the individual differences they can create. Due to all of this, the fact that language is built through a complex inter- 
action of linguistic and non-linguistic cognitive processes has been neglected. Executive functions are especially important in this respect, because they can be considered organisational processes involved in many of levels of learning (Guralnick, 2011).

In the early days of research on executive functions, the focus was primarily on their description, and these functions were investigated independently of their relationships to other cognitive domains. Recently, the emphasis has shifted to developmental relationships between executive functions, theory of mind, and other cognitive domains (Carlson \& Moses, 2001; Carlson, Mandell, \& Williams, 2004; Gordon \& Olson, 1998).

Various authors define executive function differently, but most agree that the executive functions include a range of interrelated processes that are responsible for goal-directed behaviour. These functions represent a "guide" that controls, organises and manages cognitive activity, emotional response and behaviour (Gioia, Isquith, \& Guy, 2001). In the literature, there are four different processes that are commonly considered executive function processes: inhibitory control, working memory, cognitive flexibility and planning (Best \& Miller, 2010; Bierman, Nix, Greenberg, Blair, \& Domitrovich, 2008).

\section{Relationship between Executive Functions and Language}

Despite the consensus in the developmental literature regarding the role of executive function (EF) skills in supporting the development of language skills during the preschool years, we know relatively little about the associations between these EF skills, their components, and language skills among preschoolaged children. The relationship between executive functions and language has been researched (Weiland, Barata, \& Yoshikawa, 2014; Welsh, Nix, Blair, Bierman, \& Nelson, 2010), but this research is less intensive than research on the relationship between executive functions and the theory of mind (and the theory of mind and language). The direction of the developmental pathways between EF skills and language skills is unclear. Some research shows that EF skills help children focus on multiple streams of information at the same time, monitor errors, and make decisions in light of available information, which is important in children's acquisition and development of initial language skills (Diamond, 2013).

Most studies have dealt with the relationship between language and working memory (e.g., Adams \& Gathercole, 1996; Baddeley, 2003; Daneman \& Merikle, 1996). Most of the authors agree that working memory consists of various mutually interacting components. Some of these components are responsible for retaining information over a short time period (short-term memory), and others are responsible for cognitive control, which regulates and coordinates the received information (Engle, 2010).

For explaining the relationship between working memory and language comprehension, it is important to consider the role of the phonological loop in the working memory model (Baddeley \& Hitch, 1974). The phonological loop is re- 
sponsible for short-term retention of verbally received information while other cognitive "tasks" are taking place, such as word retrieval or spoken message comprehension (Baddeley, Gathercole, \& Papagno, 1998). In most of the relevant research on pre-school children, verbal working memory is operationalised as nonsense-word repetition. Most studies confirm the positive relationship between working memory and language learning in pre-school children (Avons, Wragg, Cupples, \& Lovegrove, 1998; Gathercole \& Baddeley, 1989). Additionally, working memory is presumed to have an important role in the development of language comprehension (Cain, Oakhill, \& Bryant, 2004), grammar and morphology acquisition (Plunkett \& Marchman, 1993; Speidel, 1993), and reading (Engle de Abreu, Gathercole, \& Martin, 2011). However, it should be noted that most studies on the relationship between working memory and language comprehension have been performed on school-aged children.

Unlike verbal tasks, spatial tasks for testing working memory have not demonstrated this relationship, and it has been found that such tasks have low correlations with tests of comprehension (Swanson \& Howell, 2001).

Research that investigates the relationship between language and inhibitory control, as well as cognitive flexibility or planning is less common than is research on the relationship between language and working memory. Inhibitory control allows the listener to choose one of various possible interpretations of a single message (Ye \& Zhou, 2008) and can potentially be related to language comprehension. However, most studies investigating the relationship between inhibitory control and language have dealt with the role of inhibitory control in either secondary language acquisition (bilingualism) (Verhoef, Roelofs, \& Chwilla, 2009) or the role of inhibitory control in conflict sentence comprehension in school children and adults (Ye \& Zhou, 2008).

Inhibitory control may have an important role in language comprehension development for the following reasons:

1) In early childhood, children most frequently acquire language through communication with their caretaker, i.e., the caretaker shows the child an object and names it. Children with typically developed inhibitory control will more easily focus on the object and thus more easily and quickly learn the meaning of new words. Additionally, these children will more quickly reallocate their mental resources and will be better synchronised in their interactions.

2) In older children, inhibitory control enables children to focus on the choice of the right word among a number of alternatives and on the choice of one of various possible interpretations of a single message (Levelt, Roelofs, \& Meyer, 1999).

3) Inhibitory control is also important in communicative perspective-taking (Brown-Schmidt, 2009; Nilsen \& Graham, 2009) and allows children to inhibit their own perspective and make use of their communicative partner's perspective. This is especially important in verbal reasoning and the comprehension of spatial language and pronouns, which are determined by 
someone's perspective.

Furthermore, cognitive flexibility is also considered to play a certain role in language development. As their vocabulary increases, children develop various expressions to describe various aspects of events, objects and persons. Moreover, due to inhibitory control and cognitive flexibility, children between three and five years old have an increased ability to adapt descriptive locutions to changing (linguistic) task cues, and the ability to adapt to changing meanings of successive verbal messages (Deák, 2004). Those abilities allow children to use language in a more flexible way.

To the best of our knowledge, there has been no research on the relationship between planning and language comprehension development. Research on children with specific language impairment has shown that they have worse planning abilities (Henry, Messer, \& Nash, 2012), even when adjustments are made for their verbal abilities. Although no conclusions could be drawn on the relationship between language and planning, these studies indicate that planning could be involved in the development of some aspects of language, e.g., its production and use (narration, conversation, persuasion). It should be noted that planning is the most complex executive function, and those tasks are saturated by inhibitory control and working memory (Senn, Espy, \& Kaufmann, 2004). Therefore, there is a distinct possibility that the relationship between planning and language comprehension is indirect. This relationship should be researched further.

It is also possible that this developmental pathway could be reversed and that language skills developed in preschool could support the acquisition and development of EF skills. It may be that better receptive vocabulary could build EF skills by enhancing children's outer and then inner speech, and this improved self-talk may then improve EF, as children become better able to plan and monitor their behaviour (Fuhs \& Day, 2011).

Generally speaking, the aforementioned research implies a connection between executive functions and language. Most research is conducted on certain aspects of executive functions (e.g., working memory), although few studies have focused on children of preschool age. This is the period of significant changes in executive functions and language comprehension. There is less research on the other aspects of executive functions. Considering the importance of inhibitory control and cognitive flexibility in language development, establishing the relationships in the preschool period can provide us with an insight into mechanisms that have not been widely studied, and might prove important for gaining understanding of children's language developmental features, in both early and later age.

This study aims to examine the relationships among various aspects of executive functions (inhibitory control, working memory, planning, and cognitive flexibility) and language comprehension. It is assumed that all aspects of executive functions will be significant predictors of language comprehension and that working memory will be the strongest predictor. 


\section{Methodology}

\subsection{Participants}

The study included 222 children between 46 and 68 months of age. The parents gave their consent and provided anamnestic data. The data were collected in five Zagreb kindergartens. Five children were excluded from further analysis because of their health issues or involvement in some form of therapy. Fourteen children participated only in one stage due to various factors (motivation, absence from kindergarten, tiredness during testing) and were therefore excluded from further analysis. The final sample included 203 children with average nonverbal cognitive development (represented by their scores on Matrix Reasoning subscaleWPPSI-III; Wechsler, 2002). The sample features are presented in Table 1.

\subsection{Measuring Instruments}

\subsubsection{Intellectual Abilities}

The Matrix Reasoning subtest (part of The Wechsler Preschool and Primary Scale of Intelligence-Third Edition; Wechsler, 2002) was used as a measure of nonverbal or general cognitive ability due to its high correlations with nonverbal $(r=0.82)$ and full ( $r=0.74)$ IQ scales (Wechsler, 2002). To ensure the sample of typically developing children, the average result on the test was used as an entry criterion.

\subsubsection{Executive Functions}

The children's executive functions were assessed by the Cambridge Neuropsychological Test Automated Battery-CANTAB) and individual tasks. CANTAB is a neuropsychological battery of tests comprising a number of touch screen computer tasks.

The children's inhibitory control was assessed by the inhibition subtest of the NEPSY-II neuropsychological battery of tests (Korkman, Kirk, \& Kemp, 2007) and by the Grass/Snow task (Gerstadt, Hong, \& Diamond, 1994). The inhibition subtest (NEPSY-II) assesses a child's ability to inhibit automatised responses and to form a new response (the child needs to say "circle" when a square is presented and "square" when a circle is presented). For the purposes of this study, the score was expressed as the number of correct responses. The Grass/Snow task requires the child to point at the white card when the experimenter says "grass" and at the green card when the experimenter says "snow." There are 16 trials in this task, and the experimenter must not remind the child of the task rules. For the purposes of this study, the score was expressed as the number of

Table 1. Sample features $(\mathrm{N}=203)$.

\begin{tabular}{ccccccccccccccc}
\hline & \multicolumn{1}{c}{ Gender } & \multicolumn{3}{c}{ Birth order } & \multicolumn{3}{c}{ Mother's education } & \multicolumn{4}{c}{ Father's education } \\
\hline N = 203 & Boys & Girls & 1 st & 2nd & 3rd - & Unqualified & High & BA & MA/PhD & Unqualified & $\begin{array}{c}\text { High } \\
\text { school }\end{array}$ & BA & MA/PhD \\
Frequency & 101 & 102 & 114 & 60 & 29 & 5 & 86 & 94 & 16 & 11 & 93 & 79 & 17 & \\
$\%$ & 49.8 & 50.2 & 56.2 & 29.6 & 14.2 & 2.5 & 42.4 & 47.3 & 7.9 & 5.4 & 45.8 & 38.9 & 8.4 \\
\hline
\end{tabular}


correct responses.

Working memory was assessed by the Digit Span task (Davis \& Pratt, 1995). The Digit Span task is a measure of verbal working memory where a child repeats the numbers in a reverse sequence. The experimenter starts with two digits and increases the digit number until the child makes a mistake twice in a row. The longest memorised sequence is recorded.

Cognitive flexibility was assessed by the CANTAB Intradimensional/Extradimensional Set Shift and by the Dimensional Change Card Sort task (Zelazo, Reznick, \& Pinon, 1995). The Intradimensional/Extradimensional Set Shift task is a computerised form of the Wisconsin Card Sorting Test (Heaton, Chelune, Talley, Kay, \& Curtiss, 1993). It consists of nine different levels. Simple stimuli are made up of just one of these dimensions, whereas compound stimuli are made up of both, namely white lines overlying colour-filled shapes. The participant starts by seeing two simple colour-filled shapes, and must learn which one is correct by touching it. Feedback teaches the participant which stimulus is correct, and after six correct responses, the stimuli and/or rules are changed. These shifts are initially intra-dimensional (e.g., colour filled shapes remain the only relevant dimension), then later extra-dimensional (white lines become the only relevant dimension). For the purpose of this study, the result is expressed as the number of completed levels within which the child shifts the cognitive set. In the Dimensional Change Card Sort task (Zelazo et al., 1995), children are required to sort a series of bivalent test cards, first according to one dimension (e.g., colour), and then according to another (e.g., shape). For the purpose of this study, the result is expressed as the number of correct answers following cognitive set shift.

Planning ability was assessed by the Stockings of Cambridge task (CANTAB), which measures spatial planning and spatial working memory. The touch screen is divided into two parts, and there are three coloured balls in each part. The participant is supposed to rearrange the balls in the bottom part of the screen so that they match the balls at the top part of the screen. The balls may be moved one at a time by touching the required ball, then touching the position to which it should be moved. The participant has to complete the task in a limited number of moves ranging from one to five. The time taken to complete the pattern and the number of moves required are taken as measures of the participant's planning ability. For the purpose of this study, the result is expressed as the minimum number of moves used to complete the task.

\subsection{Language Comprehension}

Language comprehension was assessed using the Language comprehension scale A of the Reynell Developmental Language Scales (Reynell \& Huntley, 1995). It assesses single words, relating two named objects, agents and actions, clausal constituents, attributes, noun phrases, locative relations, verbs and thematic role assignment, vocabulary and complex grammar and inference. The child should respond on the verbal order by pointing or replacing the figures. It 
consists of 67 items in total. Every successfully completed item awards one point, and the scale total represents the final result. The scale has been translated and adapted for Croatian speakers (Reynell \& Huntley, 1995, translated by Nada Lovrić).

The list of the tests and tasks used in this study is presented in Table 2.

\subsubsection{Procedure}

All of the participants were assessed individually. The research was conducted in five kindergartens in Zagreb between April 2010 and April 2011. The children's parents filled in sociodemographic questionnaires and signed informed consent forms. Each child was assessed twice with a short interval in between (two to three days).

To ensure that only children with typical cognitive development were included, the Matrix Reasoning nonverbal subtest (Wechsler Preschool and Primary Scale of Intelligence-Third edition; Wechsler, 2002) was used before the basic assessment. The sequence of tests and tasks in the sample was varied randomly to control the effect of training and tiredness on the test scores.

The first part of the assessment took approximately $40 \mathrm{~min}$. The children were assessed using the Reynell Developmental Language Scales (Reynell \& Huntley, 1995) and tasks for executive function assessment (the Grass/Snow and Dimensional Change Card Sort tasks). In the second part of the assessment, the children underwent the executive function assessment tasks of the CANTAB

Table 2. Measuring instruments.

\begin{tabular}{|c|c|c|c|c|c|c|}
\hline & & Task or subscale (Scale) & Author(s) & Scoring criteria & $\begin{array}{l}\text { Min - } \\
\operatorname{Max}\end{array}$ & $\begin{array}{l}\text { Cronbach's } \\
\text { alpha }\end{array}$ \\
\hline \multicolumn{2}{|c|}{ Intellectual abilities } & $\begin{array}{l}\text { Matrix Reasoning (The Wechsler } \\
\text { Preschool and Primary Scale of } \\
\text { Intelligence, 3rd Edition) }\end{array}$ & Wechsler, 2002 & $\begin{array}{c}\text { Number of correct } \\
\text { answers }\end{array}$ & $0-29$ & 0.78 \\
\hline \multirow{2}{*}{\multicolumn{2}{|c|}{ Inhibition }} & Inhibition subtest (NEPSY-II) & $\begin{array}{c}\text { Korkman, Kirk, \& } \\
\text { Kemp, } 2007\end{array}$ & $\begin{array}{c}\text { Number of correct } \\
\text { answers }\end{array}$ & $0-40$ & 0.93 \\
\hline & & Grass/Snow task & $\begin{array}{c}\text { Gerstadt et al., } \\
1994\end{array}$ & $\begin{array}{l}\text { Number of correct } \\
\text { answers }\end{array}$ & $0-16$ & 0.93 \\
\hline \multirow{4}{*}{$\begin{array}{l}\text { Executive } \\
\text { functions }\end{array}$} & $\begin{array}{l}\text { Working } \\
\text { memory }\end{array}$ & Digit Span Task & $\begin{array}{l}\text { Davis \& Pratt, } \\
1995\end{array}$ & $\begin{array}{l}\text { Number of items in the } \\
\text { longest sequence child } \\
\text { memorized }\end{array}$ & $0-5$ & \\
\hline & \multirow{2}{*}{$\begin{array}{l}\text { Cognitive } \\
\text { flexibility }\end{array}$} & $\begin{array}{l}\text { Intradimensional/Extradimensional } \\
\text { Set Shift (CANTAB) }\end{array}$ & $\begin{array}{c}\text { Cambridge } \\
\text { Cognition } \\
\text { CANTAB Tests }\end{array}$ & $\begin{array}{c}\text { Number od } \\
\text { completed stages }\end{array}$ & $1-9$ & 0.72 \\
\hline & & Dimensional Change Card Sort & Zelazo et.al., 1995 & $\begin{array}{c}\text { Number of correct } \\
\text { answers after set shifting }\end{array}$ & $0-6$ & 0.65 \\
\hline & Planning & Stockings of Cambridge (CANTAB) & $\begin{array}{c}\text { Cambridge } \\
\text { Cognition } \\
\text { CANTAB Tests }\end{array}$ & $\begin{array}{l}\text { Number of tasks } \\
\text { copmleted with a } \\
\text { minimum number of } \\
\text { moves }\end{array}$ & $0-12$ & 0.77 \\
\hline Language & prehension & $\begin{array}{c}\text { Language comprehension scale A } \\
\text { (Reynell Developmental Language } \\
\text { Scales) }\end{array}$ & $\begin{array}{l}\text { Reynell \& } \\
\text { Huntley, } 1995 \\
\text { (Croatian } \\
\text { adaptation) }\end{array}$ & $\begin{array}{l}\text { Number of correct } \\
\text { answers }\end{array}$ & $0-67$ & 0.75 \\
\hline
\end{tabular}


neuropsychological battery of tests (Intradimensional/Extradimensional Set Shift and Stockings of Cambridge tasks). This part took approximately $40 \mathrm{~min}$.

\subsubsection{Statistical Analysis}

In order to meet the goal of the research the correlation analysis and hierarchical regression analysis were conducted. To determine the relationship between executive functions and language comprehension hierarchical regression analysis were conducted, and the variables were introduced in two stages. In the first stage, the contribution of the control variables (age, gender, mother's education) to the explanation of variance of language comprehension were introduced; and in the second stage, the various aspects of executive functions were introduced.

\subsubsection{Results}

The analyses conducted to address the aim of the research included the statistical control of variables, besides the independent variables, that might affect dependent variable. Age control was performed in accordance with theoretical assumptions on the factors related to executive function (Fuster, 2002) and language comprehension (Berk, 2006). Research shows that as the child grows, it develops executive functions and language comprehension abilities.

It should also be noted that despite the fact that much of the current research 'does not support gender differences in either executive functions or language comprehension tasks, some research has found that girls scored higher on language tests (Hyde \& Linn, 1988). The data analyses on gender differences confirm a statistically significant difference between boys and girls on certain variables. Consequently, gender is also a controlled variable. Research also shows that the mother's education is moderately correlated with executive functions (Sarsour et al., 2011) and has low to moderate correlation with language competence tasks (Foy \& Mann, 2003). For these theoretical reasons, the mother's education is also controlled. Research has not clearly established the role of the father's education in predictors and criterion variables, and given that the mother's education is highly correlated with father's education $((r=0.5 ; p<$ $0.01)$, the father's education variable is removed from further analyses.

When analysing the missing values, we did not find a systematic pattern in the participants' failure to reply. Relatively few of the missing values were removed from analyses.

The descriptive statistics for each of the measures are shown in Table 3.

The correlations between all variables included in the study are shown in Table 4. The correlations between executive function tasks and language comprehension were all significant (low to moderate correlations), except for the correlation between the Intradimensional/Extradimensional Set Shift and language comprehension. In addition, the correlations among the executive functions tasks were also low to moderate. The lowest correlations with other variables of executive functions have been recorded for Intra/Extradimensional Set Shift subtest. 
Table 3. The descriptive statistics for nonverbal cognitive ability, executive functions and language comprehension (CA = cognitive ability; IN = inhibitory control; $\mathrm{WM}=$ working memory; $\mathrm{CF}=$ cognitive flexibility; $\mathrm{PL}=$ planning; $\mathrm{LC}$ = language comprehension).

\begin{tabular}{|c|c|c|c|c|c|c|}
\hline & Test/task & $\mathrm{N}$ & M & $\mathrm{SD}$ & Min & Max \\
\hline $\mathrm{CA}$ & Matrix Reasoning subtest & 203 & 14.4 & 3.75 & 7 & 26 \\
\hline IN & Inhibition subtest & 196 & 28.83 & 9.68 & 0 & 40 \\
\hline IN & Grass/Snow & 203 & 12.53 & 4.53 & 0 & 16 \\
\hline WM & Digit Span & 202 & 0.89 & 1.16 & 0 & 4 \\
\hline $\mathrm{CF}$ & Dimensional Change Card Sort & 203 & 5.21 & 1.23 & 0 & 6 \\
\hline $\mathrm{CF}$ & Intra-/Extradimensional Set Shift & 201 & 7.29 & 0.94 & 2 & 9 \\
\hline PL & Stockings of Cambridge & 203 & 4.07 & 2.89 & 0 & 10 \\
\hline LC & Reynell Developmental Language Scales & 203 & 57.86 & 4.53 & 44 & 67 \\
\hline
\end{tabular}

Table 4. The correlation between all variables included in study (IN = inhibitory control; WM = working memory; CF = cognitive flexibility; $\mathrm{PL}=$ planning).

\begin{tabular}{|c|c|c|c|c|c|c|c|c|c|c|}
\hline & & 2 & 3 & 4 & 5 & 6 & 7 & 8 & 9 & 10 \\
\hline & 1. Age & - & - & $0.31^{\star *}$ & $0.32^{\star *}$ & $0.51^{\star *}$ & $0.51^{\star *}$ & $0.28^{\star *}$ & - & $0.42^{* *}$ \\
\hline & 2. Gender ${ }^{\mathrm{a}}$ & & - & - & $0.18^{\star}$ & - & - & $0.14^{\star}$ & - & $0.14^{*}$ \\
\hline & 3. Mother's education ${ }^{\mathrm{b}}$ & & & - & - & - & - & - & - & $0.21^{\star *}$ \\
\hline IN & 4. Inhibition subtest & & & & $0.40^{* *}$ & $0.32^{* *}$ & $0.38^{\star *}$ & $0.25^{\star *}$ & $0.19^{*}$ & $0.42^{* *}$ \\
\hline $\mathrm{IN}$ & 5. Grass/Snow task & & & & & $0.32^{* *}$ & $0.42^{\star \star}$ & $0.36^{\star \star}$ & - & $0.48^{* *}$ \\
\hline WM & 6. Digit span & & & & & & $0.46^{\star *}$ & $0.25^{\star \star}$ & $0.17^{\star}$ & $0.54^{\star *}$ \\
\hline PL & 7. Stockings of Cambridge & & & & & & & $0.36^{\star *}$ & - & $0.47^{\star *}$ \\
\hline $\mathrm{CF}$ & $\begin{array}{l}\text { 8. Dimensional Change } \\
\text { Card Sort }\end{array}$ & & & & & & & & $0.17^{\star}$ & $0.33^{* *}$ \\
\hline $\mathrm{CF}$ & $\begin{array}{l}\text { 9. Intra/Extradimensional } \\
\text { Set Shift }\end{array}$ & & & & & & & & & - \\
\hline & 10. Language comprehension & & & & & & & & & \\
\hline
\end{tabular}

${ }^{*} \mathrm{p}<.05 ;{ }^{*} \mathrm{p}<.01 ;{ }^{\mathrm{a}} 1$ = Male, $2=$ Female; ${ }^{\mathrm{b}}$ from 1 (unqualified) to 4 (MA/PhD).

Table 5 shows the results of the hierarchical regression analysis. The control variables explained $25 \%$ of the criterion variance, and all of these variables were significant predictors. Introducing the executive function tasks in the second stage explained an additional $21 \%$ of the criterion variance. The Digit Span and Grass/Snow tasks were the only significant predictors of language comprehension. It is apparent that control variables are significant variables in the first stage, whereas in the following stage the variables of age and gender become statistically insignificant. This may lead to the conclusion that impact of those variables can be seen through executive functions variables. $B$ coefficient for the mother's education variable retained statistical significance, even after the introduction of executive function tasks into the regression equation. 
Table 5. The relationship between executive functions and language comprehension-the results of a hierarchical regression analysis.

\begin{tabular}{|c|c|c|c|}
\hline & & 1st stage & 2nd stage \\
\hline & Predictors & \multicolumn{2}{|c|}{ Standardized Coefficients Beta } \\
\hline & Age & $0.17^{\star}$ & 0.10 \\
\hline & Gender $^{\mathrm{a}}$ & $0.15^{\star}$ & 0.08 \\
\hline & Mother's education ${ }^{\mathrm{b}}$ & $0.27^{\star *}$ & $0.19^{* *}$ \\
\hline IN & Inhibition subtest & & 0.12 \\
\hline $\mathrm{IN}$ & Grass/snow task & & $0.22^{\star *}$ \\
\hline WM & Digit span task & & $0.27^{\star *}$ \\
\hline PL & Stockings of Cambridge & & 0.12 \\
\hline $\mathrm{CF}$ & Dimensional Change Card Sort & & 0.09 \\
\hline \multirow[t]{5}{*}{$\mathrm{CF}$} & Intra-/Extradimensional Set Shift & & -0.02 \\
\hline & Model summary: & & \\
\hline & $\mathrm{R}$ & $0.52^{\star *}$ & $0.70^{* *}$ \\
\hline & $\mathrm{R}^{2}$ kor (Adjusted R Square) & $0.25^{\star *}$ & $0.46^{* *}$ \\
\hline & $\Delta \mathrm{R}^{2}$ (R Square Change) & $0.25^{\star *}$ & $0.21^{\star *}$ \\
\hline
\end{tabular}

${ }^{*} p<0.05 ;{ }^{* *} p<0.01 ;{ }^{\mathrm{a}} 1=$ Male, $2=$ Female; ${ }^{\mathrm{b}}$ from 1 (unqualified) to $4(\mathrm{MA} / \mathrm{PhD})$.

\section{Discussion}

Studies that investigate the relationship between executive functions and language have focused mostly on the relationship between language abilities and verbal working memory (Avons et al., 1998). Other executive functions have been examined sparsely and specifically in some populations, e.g., inhibitory control (Verhoef et al., 2009) and cognitive flexibility (Deák, 2003), which have been predominantly examined in bilingual populations.

Accordingly, the aim of our study was to determine the relationship between various aspects of the executive functions (inhibitory control, working memory, cognitive flexibility and planning) and language comprehension in preschool children.

The investigation of the relationship between executive functions and language showed that the most significant predictors of language comprehension were those aspects of executive functions: verbal working memory, as assessed by the Digit Span task, and inhibitory control, as assessed by the Grass/Snow task.

\subsection{Language Comprehension and Inhibitory Control}

Inhibitory control, as assessed by the Grass/Snow task, was a significant predictor of language comprehension. This result was expected because inhibitory control as assessed by conflict tasks was presumed to have an important role in language comprehension development. If we consider the variable of language comprehension, we can see that at this age it integrates semantic and morphosyntactic knowledge, as well as the comprehension of role attribution, adjective gradation, 
spatial relations, quantifiers and verbal deduction. Because all of these are context-dependent, inhibitory control has an important role in focusing on a new context and in inhibiting the previously correct answer and the previous context. Additionally, while using the Reynell Developmental Language Scale, we noticed that children who had less mature inhibitory control, despite the experimenter's instruction, reached for an object from the test material that they found attractive or interesting, which is why they achieved a lower result in the language comprehension domain. Accordingly, we can conclude that inhibitory control is an important ability and has an important role in the relationship between executive functions and language comprehension.

In this study, two tasks were used for assessing inhibitory control: the Inhibition Subtest and the Grass/Snow task. The correlation between these tasks was moderate. The difference between the two inhibitory control tasks used in this study is that the input in the Grass/Snow task is verbal and the child's output is nonverbal (showing), but the input in the Inhibition subtest is visual (nonverbal) and the child's output is verbal. We believe that the Grass/Snow task is a significant predictor of language comprehension because the mechanisms needed to resolve this task are similar to the mechanisms and networks involved in a language comprehension task-one needs to comprehend linguistic input, consider among possible alternatives, inhibit inappropriate (conflicted) semantic item(s) and give nonverbal (hand motor) output. Previous studies have already shown that, although the inhibition of spoken and manual responses share common neural substrates (Xue, Aron, \& Poldrack, 2008), specific cortical areas have different contributions to cognitive control, which is based on the source of conflict (Nelson, Reuter-Lorenz, Sylvester, Jonies, \& Smith, 2003) and the characteristics of the task itself (verbal vs. visuospatial) (Stephan et al., 2003).

\subsection{Language Comprehension and Working Memory}

Verbal working memory, as assessed with the Digit Span task, was a significant predictor of language comprehension. Working memory has also been shown to be an important predictor of language development in toddlers (Stokes \& Klee, 2009) and a relevant factor involved in language acquisition (Avons et al., 1998; Gathercole \& Baddeley, 1989) and reading (Goff, Pratt, \& Ong, 2005). In the preschool period, working memory is involved in the comprehension of longer utterances and structurally and semantically complex sentences. While listening to instructions, the listener must decode the words, understand the syntax, retain the words in memory, take context into consideration, and have typically developed receptive vocabulary. The listener has to do all of this simultaneously in order to understand the entire sentence. Because phonological working memory is important for the short-term retention of verbally received information while other cognitive "tasks" are taking place (e.g., comprehension of words or spoken messages) (Baddeley et al., 1998), it is clear that verbal working memory has an important role in language comprehension development. A meta-analysis of 77 studies that investigated the association between working-memory capacity 
and language comprehension ability showed that the results on verbal working memory tasks were good predictors of language comprehension and that measures that tap the combined processing and storage resources of working memory (e.g., reading span) are better predictors of comprehension than measures that tap only the storage resources (e.g., digit span) (Daneman \& Merikle, 1996).

Verbal working memory capacity shows a positive correlation with language production (Adams \& Gathercole, 1995, 1996) and language comprehension (Montgomery, 1995) in both typically developing children and children with language impairments.

When commenting on our results, we should also consider that two executive function tasks that were associated with language comprehension, Digit Span Backward and Grass/Snow task, are both verbal tasks. Thus, the association between these EF domains and language comprehension could be due to the shared verbal demands of the different tasks, rather than an actual association between inhibition and working memory on the one hand and language comprehension on the other.

\subsection{Language Comprehension and Cognitive Flexibility}

Cognitive flexibility, as assessed with the Intradimensional/Extradimensional Set Shift and Dimensional Change Card Sort tasks, was not a significant predictor of language comprehension. This can be partly explained by the executive functions model, which views executive function as a supervisory attentional system (Norman \& Shallice, 1986). According to this model, if we are solving a non-automatised problem, mental activity has to be wilfully directed. Shallice and Burgess (1996) believe that the supervisory system consists of three phases. In the first phase, a new cognitive pattern for a new situation is created, and new strategies are created, most frequently by a problem-solving technique. In the second phase, the created pattern is applied. In the third phase, this pattern is supervised and rejected if shown to be inappropriate. All of these processes take place when the child is faced with a new activity or task. Cognitive flexibility tasks have not been found to be significant predictors of language comprehension because children of this age have already acquired the names of colours, prepositions and pronouns; their knowledge has been automated; and cognitive patterns have been formed and activated to help perform the automated activity and inhibit other conflicting cognitive patterns (Norman \& Shallice, 1986). At this age, the processes of cognitive flexibility are no longer "crucial" for successful performance on complex language comprehension tests. If we look at table 3, it is obvious that for both tasks that measure cognitive flexibility children achieved, on average, almost maximum results. That means that in our sample, those tasks did not have good sensitivity and that may be why we did not find any relationship between cognitive flexibility and language comprehension. In addition, cognitive flexibility may be important for communication skills and for situations when a person has to adjust to different communicative partners, but if we look clearly at how children adopt the meaning of the words, cognitive 
flexibility may not be a crucial mechanism.

\subsection{Language Comprehension and Planning}

Planning, as assessed with the Stocking of Cambridge (CANTAB) task, was not a significant predictor of language comprehension. To the best of our knowledge, there has been no research on the relationship between planning and language comprehension development. Considering the fact that planning ability is the most complex executive functions task and is saturated by inhibitory control and working memory (Senn et al., 2004) we assumed that planning ability would be a significant predictor of language comprehension; however, that assumption has not been confirmed.

The analyses may suggest that task impurity could account for the stronger relations between Grass/Snow and Digit Span task with comprehension, with all the tasks involving some aspects of language ability. Therefore, we performed further analyses by removing the language assessments from the regression analysis and determining whether the non-verbal executive functions measures were significant predictors. The results show that Dimensional Change Card Sort (cognitive flexibility) and Stocking of Cambridge (planning) tasks were significant predictors of language comprehension, so the non-significant relations in our results may be explained by task impurity. This task impurity problem affects all studies of children's EF and is further compounded by the fact that the construct validity for most EF tasks has not been well established.

\subsection{Limitations and Future Directions}

Before drawing any conclusions, it is necessary to view the obtained results in the light of certain limitations that reduce their generalisability and point to the need for further research of the relationships between executive functions and language comprehension.

A considerable methodological problem in studying executive functions is the lack of solid evidence on the validity and reliability of the tasks used. In the executive functions assessment, two types of "errors" are encountered. One type of error is related to the multifactorial nature of executive tasks, so it is not clear which aspects of the executive functions the tasks measure (e.g., most of the tasks that measure inhibitory control also measure working memory) or to what extent the success on a certain task is influenced by a certain aspect of executive functions. The second type of "error" is related to the fact that the task performance can depend not only on executive functions but also on other abilities and other levels of information processing skills and response making. Therefore, a successful performance on such tasks might include the processes of visual perception, motor skills, processing speed, etc. For all of these reasons, poor task performance can be a consequence of executive functions impairment or can have a contributing cause in the impairment of some other function.

It is important to note that the assessment of executive functions at an early age mostly includes specifically designed but non-standardised tasks. Even today 
there are only a few standardised instruments for assessing executive functions in children, e.g., the computerised CANTAB test and the Attention and Executive Functions domain in a Neuropsychological Assessment-II (NEPSY-II). The lack of standardised tests has long prevented researchers from identifying individual differences and detecting deviations in the development of executive functions and following their developmental trajectories by longitudinal research. Additionally, some of the limitations are related to CANTAB. Although CANTAB can be used during the entire life-span (four to 90 years), we noticed that some of the tasks were difficult and/or boring for the four-year-old children, and sometimes it was hard to say whether the task performance was actually the result of a child's capability or of motivation and fatigue. Additionally, the four-year-old children had greater difficulties in working with the touch screen. Although the measuring instruments using touch screen are considered to be reliable, some children have problems due to their lack of experience with this type of response making. In such cases, we cannot say whether the child did not understand the instruction or whether the screen is not sensitive enough to detect the child's touch or hand temperature (Luciana \& Nelson, 2002). Furthermore, the four-year-old children sometimes had difficulties in understanding the instructions, especially in the Cambridge Stockings task. The study by Luciana and Nelson (1998) showed that approximately $50 \%$ of the four-year-old children had difficulties in understanding the instruction in this task. All of the mentioned limitations related to CANTAB might have caused lower reliability coefficients than expected.

Additionally, we used the Reynell Developmental Language Scale as a measure of language development. However, this scale is a "broad" measure of language comprehension. Thus to determine more precise relationships further research should use more specific scales that assess one language segment, i.e., assess aspects of language development that are strictly defined.

Due to all of the listed factors that can influence the final score on the executive functions assessment tasks in children, it is advisable to consider both quantitative (e.g., percent correct, time taken) and qualitative measures of the performance (e.g., frequency of rule-violations, displays of frustration or distractibility) when analysing and interpreting the results. In most executive functions assessment tasks, performance is evaluated as the sum of all accurately solved items. In this way, the total final quantitative result is affected by a range of both executive and non-executive abilities. The control of such factors, i.e., at least those that are reflected in the child's behaviour and are visible to the experimenter, could contribute to a better interpretation of the obtained results.

Despite the listed limitations, the strength of this research lies in the fact that it determines the relationships between various aspects of executive functions and language comprehension in typical Croatian pre-school children. This study confirmed the important role of inhibitory control and verbal working memory for the development of language comprehension. Additionally, this research has numerous practical implications. Understanding the relationship between ex- 
ecutive functions and language comprehension in children with typical development is a necessary prerequisite for understanding some developmental disorders. Developmental disorders with recorded impairments in at least one developmental domain are: autism spectrum disorder, attention deficit and hyperactivity disorder, and specific language impairments (Bishop \& Norbury, 2005; Corbett, Constantine, Hendren, Rocke, \& Ozonoff, 2009; Girli \& Tekin, 2010; Robinson, Goddard, Dritschel, Wisley, \& Howlin, 2009; Hill, 2004; Tirosh \& Cohen, 1998).

Understanding these relationships is important for the diagnostics and treatment of developmental disorders. The authors' clinical experience shows that it is important to consider this relationship in children's assessment and treatment planning. For example, when using the Language Comprehension Scale, the clinician has to be able to discern whether the child is making a mistake because he or she has primary problems with working memory and/or inhibitory control and consequently in language understanding or due to some other cognitive difficulties (e.g., perceptive). It is clear that good developmental assessment influences the choice of treatment procedures and the planning of individualised programs for children with developmental difficulties, both of preschool and school age. The practice so far has shown that the relationship between executive functions and language has (unreasonably) been given too little attention in the planning of treatment procedures.

\section{References}

Adams, A. M., \& Gathercole, S. E. (1995). Phonological Working Memory and Speech Production in Pre-School Children. Journal of Speech and Hearing Research, 38, 403414. https://doi.org/10.1044/jshr.3802.403

Adams, A. M., \& Gathercole, S. E. (1996). Phonological Working Memory and Spoken Language Development in Young Children. Quarterly Journal of Experimental Psychology Section A: Human Experimental Psychology, 49, 216-233. https://doi.org/10.1080/713755610

Avons, S., Wragg, C., Cupples, L., \& Lovegrove, W. (1998). Measures of Phonological Short-Term Memory and Their Relationship to Vocabulary Development. Applied Psycholinguistics, 19, 537-552. https://doi.org/10.1017/s0142716400010377

Baddeley, A. (2003). Working Memory and Language: An Overview. Journal of Communication Disorders, 36, 189-208. https://doi.org/10.1016/S0021-9924(03)00019-4

Baddeley, A. D., \& Hitch, G. J. (1974). Working Memory. In G. Bower (Ed.), The Psychology of Learning and Motivation (Vol. 8, pp. 47-89). Academic Press: New York. https://doi.org/10.1016/s0079-7421(08)60452-1

Baddeley, A. D., Gathercole, S., \& Papagno, C. (1998). The Phonological Loop as a Language Learning Device. Psychological Review, 105, 158-173.

https://doi.org/10.1037/0033-295X.105.1.158

Berk, L. E. (2006). Child Development. Boston: Pearson Education.

Best, J. R., \& Miller, P. H. (2010). A Developmental Perspective on Executive Function. Child Development, 81, 1641-1660. https://doi.org/10.1111/j.1467-8624.2010.01499.x

Bierman, K. L., Nix, R. L., Greenberg, M. T., Blair, C., \& Domitrovich, C. E. (2008). Executive Functions and School Readiness Intervention: Impact, Moderation, and 
Mediation in the Head Start REDI Program. Development and Psychopathology, 20, 821-843. https://doi.org/10.1017/S0954579408000394

Bishop, D. V. M., \& Norbury, C. F. (2005). Executive Functions in Children with Communication Impairments, in Relation to Autistic Symptomatology. 2: Response Inhibition. Autism, 9, 29-43. https://doi.org/10.1177/1362361305049028

Brown-Schmidt, S. (2009). The Role of Executive Function in Perspective Taking during Online Language Comprehension. Psychonomic Bulletin \& Review, 16, 893-900. https://doi.org/10.3758/PBR.16.5.893

Cain, K., Oakill, J., \& Bryant, P. E. (2004). Children's Reading Comprehension Ability: Concurrent Prediction by Working Memory, Verbal Ability, and Component Skills. Journal of Educational Psychology, 96, 31-42. https://doi.org/10.1037/0022-0663.96.1.31

Carlson, S. M., \& Moses, L. J. (2001). Individual Differences in Inhibitory Control and Children's Theory of Mind. Child Development, 72, 1032-1053. https://doi.org/10.1111/1467-8624.00333

Carlson, S. M., Mandell, D. J., \& Williams, L. (2004). Executive Function and Theory of Mind: Stability and Prediction from Ages 2 to 3. Developmental Psychology, 40, 11051122. https://doi.org/10.1037/0012-1649.40.6.1105

Corbett, B. A., Constantine, L. J., Hendren, R., Rocke, D., \& Ozonoff, S. (2009). Examining Executive Functioning in Children with Autism Spectrum Disorder, Attention Deficit Hyperactivity Disorder and Typical Development. Psychiatry Research, 166, 210-222. https://doi.org/10.1016/j.psychres.2008.02.005

Daneman, M., \& Merikle, P. M. (1996). Working Memory and Language Comprehension: A Meta-Analysis. Psychonomic Bulletin and Review, 3, 422-433. https://doi.org/10.3758/BF03214546

Davis, H. L., \& Pratt, C. (1995). The Development of Children's Theory of Mind: The Working Memory Explanation. Australian Journal of Psychology, 47, 25-31. https://doi.org/10.1080/00049539508258765

Deák, G. O. (2004). The Development of Cognitive Flexibility and Language Abilities. Advances in Child Development and Behavior, 31, 271-327. https://doi.org/10.1016/S0065-2407(03)31007-9

Diamond, A. (2013). Executive Functions. Annual Review of Psychology, 64, 135-168. https://doi.org/10.1146/annurev-psych-113011-143750

Engle de Abreu, P. M. J., Gathercole, S. E., \& Martin, R. (2011). Disentangling the Relationship between Working Memory and Language: The Roles of Short-Term Storage and Cognitive Control. Learning and Individual Differences, 21, 569-574. https://doi.org/10.1016/j.lindif.2011.06.002

Engle, R. W. (2010). Role of Working Memory Capacity in Cognitive Control. Current Anthropology, 51, S17-S26. https://doi.org/10.1086/650572

Foy, J. G., \& Mann, V. A. (2003). Home Literacy Environment and Phonological Awareness in Preschool Children: Differential Effects for Rhyme and Phoneme Awareness. Applied Psycholinguistics, 24, 59-88. https://doi.org/10.1017/S0142716403000043

Fuhs, M. W., \& Day, J. D. (2011). Verbal Ability and Executive Functioning Development in Preschoolers at Head Start. Developmental Psychology, 47, 404-416. https://doi.org/10.1037/a0021065

Fuster, J. M. (2002). Frontal Lobe and Cognitive Development. Journal of Neurocytology, 31,373-385. https://doi.org/10.1023/A:1024190429920

Gathercole, S., \& Baddeley, A. (1989). Evaluation of the Role of Phonological STM in the 
Development of Vocabulary in Children: A Developmental Study. Journal of Memory and Language, 28, 200-213. https://doi.org/10.1016/0749-596X(89)90044-2

Gerstadt, C. L., Hong, Y. J., \& Diamond, A. (1994). The Relationship between Cognition and Action: Performance of Children 31/2-7 Years Old on Stroop-Like Day-Night Test. Cognition, 53, 129-153. https://doi.org/10.1016/0010-0277(94)90068-X

Gioia, G. A., Isquith, P. K., \& Guy, S. C. (2001). Assessment of Executive Functions in Children with Neurological Impairment. In: R. J. Simeonsson, \& L. Rosenthal (Eds.), Psychological and Developmental Assessment: Children with Disabilities and Chronic Conditions (pp. 317-356). New York: Guilford Press.

Girli, A., \& Tekin, D. (2010). Investigating False Belief Levels of Typically Developed Children and Children with Autism. Procedia-Social and Behavioral Sciences, 2, 1944-1950. https://doi.org/10.1016/j.sbspro.2010.03.261

Goff, D. A., Pratt, C., \& Ong, B. (2005) The Relations between Children's Reading Comprehension, Working Memory, Language Skills and Components of Reading Decoding in a Normal Sample. Reading and Writing, 18, 583-616.

https://doi.org/10.1007/s11145-004-7109-0

Gordon, A. C. L., \& Olson, D. R. (1998). The Relation between Acquisition of a Theory of Mind and the Capacity to Hold in Mind. Journal of Experimental Child Psychology, 68, 70-83. https://doi.org/10.1006/jecp.1997.2423

Guralnick, M. J. (2011) Why Early Intervention Works: A Systems Perspective. Infants \& Young Children, 24, 6-28. https://doi.org/10.1097/IYC.0b013e3182002cfe

Heaton, R. K., Chelune, G. J., Talley, J. L., Kay, G. G., \& Curtiss, G. (1993). Wisconsin Card Sorting Test Manual: Revised and Expanded. Odessa, FL: Psychological Assessment Resources.

Henry, L.A., Messer, D.J., \& Nash, G. (2012). Executive Functioning in Children with Specific Language Impairment. Journal of Child Psychology and Psychiatry and Allied Disciplines, 53, 37-45. https://doi.org/10.1111/j.1469-7610.2011.02430.x

Hill, E. L. (2004). Executive Dysfunction in Autism. Trends in Cognitive Sciences, 8, 26-32. https://doi.org/10.1016/j.tics.2003.11.003

Hyde, J., \& Linn, M. (1988). Gender Differences in Verbal Ability: A Meta-Analysis. Psychological Bulletin, 104, 53-69. https://doi.org/10.1037/0033-2909.104.1.53

Korkman, M., Kirk, U., \& Kemp, S. (2007). NEPSY—Second Edition (NEPSY-II). San Antonio, TX: Harcourt Assessment.

Levelt, W. J. M., Roelofs, A., \& Meyer, A. S. (1999). A Theory of Lexical Access in Speech Production. Behavioral and Brain Sciences, 22, 1-75. https://doi.org/10.1017/S0140525X99001776

Luciana, M., \& Nelson, C. A. (1998). The Functional Emergence of Prefrontally Guided Working Memory Systems in Four-to-Eight Year-Old Children. Neuropsychologia, 36, 272-293. https://doi.org/10.1016/S0028-3932(97)00109-7

Luciana, M., \& Nelson, C. A. (2002). Assessment of Neuropsychological Function through Use of the Cambridge Neuropsychological Testing Automated Battery: Performance in 4- to 12- Year-Old Children. Developmental Neuropsychology, 22, 595-624. https://doi.org/10.1207/S15326942DN2203_3

Montgomery, J. W. (1995). Sentence Comprehension in Children with Specific Language Impairment: The Role of Phonological Working Memory. Journal of Speech and Hearing Research, 38, 187-199. https://doi.org/10.1044/jshr.3801.187

Nelson, J. K., Reuter-Lorenz, P. A., Sylvester, C. Y. C., Jonied, J., \& Smith, E. E. (2003). Dissociable Neural Mechanisms Underlying Response-Based and Familiarity-Based Conflict in Working Memory. Proceedings of the National Academy of Sciences of the 
Nilsen, E. S., \& Graham, S. A. (2009). The Relations between Children's Communicative Perspective-Taking and Executive Functioning. Cognitive Psychology, 58, 220-249. https://doi.org/10.1016/j.cogpsych.2008.07.002

Norman, D. A., \& Shallice, T. (1986). Attention to Action: Willed and Automatic Control of Behaviour. In: R. J. Davidson., G. E. Schwartz, \& D. E. Shapiro (Eds.), Consciousness and Self-Regulation (pp. 1-14). New York: Plenum Press.

Plunkett, K., \& Marchman, V. (1993). From Rote Learning to System-Building: Acquiring Verb Morphology in Children and Connectionist Nets. Cognition, 48, 21-69. https://doi.org/10.1016/0010-0277(93)90057-3

Reynell, J. K., \& Huntley, M. (1995). Priručnik za Reynell razvojne ljestvice govora. Jastrebarsko: Naklada Slap.

Robinson, S., Goddard, L., Dritschel, B., Wisley, M., \& Howlin, P. (2009). Executive Functions in Children with Autism Spectrum Disorder. Brain and Cognition, 71, 362-368. https://doi.org/10.1016/j.bandc.2009.06.007

Sarsour, K., Sheridan, M., Jutte, D., Nuru-Jeter, A., Hinshaw, S., \& Boyce, W. T. (2011). Family Socioeconomic Status and Child Executive Functions: The Roles of Language, Home Environment, and Single Parenthood. Journal of the International Neuropsychological Society, 17, 120-132. https://doi.org/10.1017/S1355617710001335

Senn, T. E., Espy, K. A., \& Kaufmann, P. M. (2004). Using Path Analysis to Understand Executive Function Organisation in Preschool Children. Developmental Neuropsychology, 26, 445-464. https://doi.org/10.1207/s15326942dn2601_5

Shallice, T., \& Burgess, P. W. (1996). The Domain of Supervisory Processes and Temporal Organisation of Behaviour. Philosophical Transactions of the Royal Society of London B: Biological Sciences, 351, 1405-1412. https://doi.org/10.1098/rstb.1996.0124

Speidel, G. (1993). Phonological Short-Term Memory and Individual Differences in Learning to Speak: A Bilingual Case Study. First Language, 13, 69-91. https://doi.org/10.1177/014272379301303705

Stephan, K. E., Marshall, J. C., Friston, K. J., Rowe, J. B., Ritzl, A., Zilles, K., \& Fink, G. R. (2003). Lateralized Cognitive Processes and Lateralized Task Control in the Human Brain. Science, 301, 384-386. https://doi.org/10.1126/science.1086025

Stokes, S. F., \& Klee, T. (2009). Factors That Influence Vocabulary Development in TwoYear-Old Children. Journal of Child Psychology and Psychiatry and Applied Disciplines, 50, 498-505. https://doi.org/10.1111/j.1469-7610.2008.01991.x

Swanson, H. L., \& Howell, M. (2001). Working Memory, Short-Term Memory, and Speech Rate as Predictors of Children's Reading Performance at Different Ages. Journal of Educational Psychology, 93, 720-734. https://doi.org/10.1037/0022-0663.93.4.720

Tirosh, E., \& Cohen, A. (1998). Language Deficit with Attention-Deficit Disorder: A Prevalent Comorbidity. Journal of Child Neurology, 13, 493-497. https://doi.org/10.1177/088307389801301005

Verhoef, K. M. W., Roelofs, A., \& Chwilla, D. J. (2009). Role of Inhibition in Language Switching: Evidence from Event-Related Brain Potentials in Overt Picture Naming. Cognition, 110, 84-99. https://doi.org/10.1016/j.cognition.2008.10.013

Wechsler, D. (2002). WPPSI-III Technical and Interpretive Manual. San Antonio, TX: The Psychological Corporation, Harcourt Assessment Company.

Weiland, C., Barata, M. C., \& Yoshikawa, H. (2014). The Co-Occurring Development of Executive Function Skills and Receptive Vocabulary in Preschool-Aged Children: A Look at the Direction of the Developmental Pathways. Infant and Child Development, 23, 4-21. https://doi.org/10.1002/icd.1829 
Welsh, J. A., Nix, R. L., Blair, C., Bierman, K. L., \& Nelson, K. E. (2010). The Development of Cognitive Skills and Gains in Academic School Readiness for Children from Low-Income Families. Journal of Educational Psychology, 102, 43-53. https://doi.org/10.1037/a0016738

Xue, G., Aron, A. R., \& Poldrack, R. A. (2008). Common Neural Substrates for Inhibition of Spoken and Manual Responses. Cerebral Cortex, 18, 1923-1932. https://doi.org/10.1093/cercor/bhm220

Ye, Z., \& Zhou, X. (2008). Involvement of Cognitive Control in Sentence Comprehension: Evidence from ERPs. Brain Research, 1203, 103-115. https://doi.org/10.1016/j.brainres.2008.01.090

Zelazo, P. D., Reznick, J. S., \& Pinon, D. E. (1995). Response Control and the Execution of Verbal Rules. Developmental Psychology, 31, 508-517.

https://doi.org/10.1037/0012-1649.31.3.508

Submit or recommend next manuscript to SCIRP and we will provide best service for you:

Accepting pre-submission inquiries through Email, Facebook, LinkedIn, Twitter, etc. A wide selection of journals (inclusive of 9 subjects, more than 200 journals)

Providing 24-hour high-quality service

User-friendly online submission system

Fair and swift peer-review system

Efficient typesetting and proofreading procedure

Display of the result of downloads and visits, as well as the number of cited articles Maximum dissemination of your research work

Submit your manuscript at: http://papersubmission.scirp.org/

Or contact psych@scirp.org 